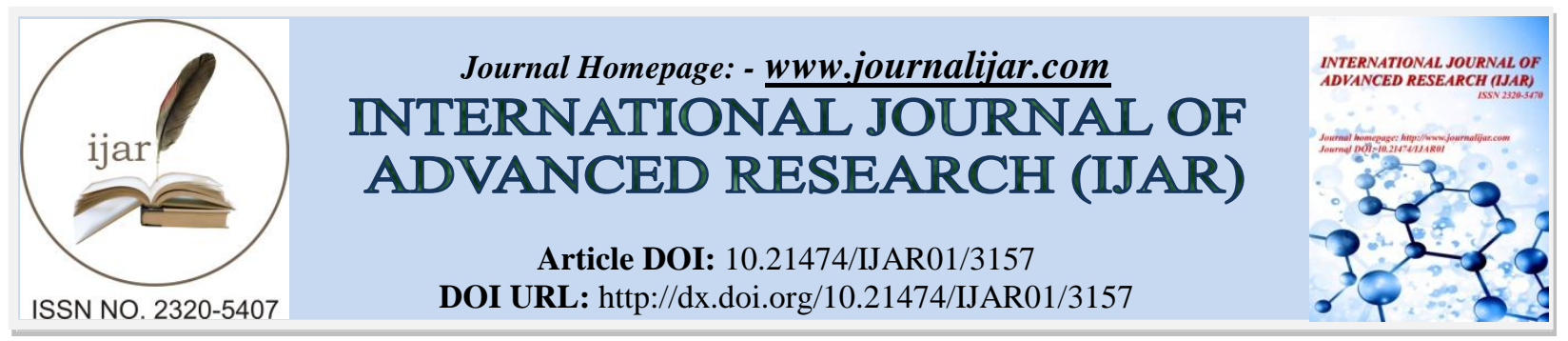

RESEARCH ARTICLE

\title{
REVIEWING ON STREET ATTRIBUTES IN INFLUENCING SENSE OF PLACE AND PLACE ATTACHMENT.
}

\section{Musaab Sami Al-Obeidy ${ }^{1}$ and Rawia Marwan Dabdoob ${ }^{2}$.}

1. Assistant Lecturer, Department of Architectural Engineering. Cihan University- Sulaimaniya.

2. Assistant Lecturer, Department of Architectural Engineering. Mosul University.

\section{Manuscript Info}

Manuscript History

Received: 18 December 2016

Final Accepted: 10 January 2017

Published: February 2017

Key words:-

Street Attributes; Street Character; Sense of Place; Place Attachment.

\begin{abstract}
Nowadays, the concept of sense of place and place attachment are threatened by new developments, urban interventions, poor design and erosion in streets of towns and cities. These threatens lead to the loss of the character of city centers. There is no doubt that the sense of place and place attachment can be created by street attributes. Thus, this paper attempts to review the attributes of city center streets that contribute in influencing sense of place and place attachment. The study postulates this question: what are the street attributes that have influences on the sense of place and place attachment? The study aims at establishing the theoretical framework of street attributes in terms of creating sense of place and place attachment. The study reveals that streets have two types of characteristics, physical and functional. These characteristics can create and enhance street attributes that include vitality, diversity, transaction, accessiblity, legibility, distinctiveness, comfort, and safety and security in terms of making place attachment, besides commerce, cultural value, social value, movement, accessibility, legibility, recognition, sense of comfort, and sense of safety in terms of making sense of place.
\end{abstract}

Copy Right, IJAR, 2017,. All rights reserved.

\section{Introduction:-}

It is worth noting, some environmental psychologists who argued the experience of place is one of the most important factors in sense of place such as, Shamai (1991), Kevin Lynch (1960), Relph (1976) and others. Those defined and explained many important definitions and concepts which related with place. In addition, they are regarded as pioneers in using experiential perspectives to reflect on place and 'sense of place'.

Relph (1976) described place as an interaction of three components i.e. 'physical setting', 'activity' and 'meaning'. While Sense of place is defined as a combination of three elements i.e. location, landscape, and personal involvement (Shamai, 1991). Spirit of place relates to the exclusive aspects of a place (Smaldone, 2006). Barker (1979) quoted from Bassett (2011), defined the sense of place as one of the most intangible concepts. Alford (2011) refers that unique identity of place is one of sense of place meanings. Moreover, she defined sense of place as relationship between people and their atmosphere.

Corresponding Author:- Musaab Sami Al-Obeidy. 
Three components that contribute in making a sense of place were referred to by Najafi and Shariff (2011); and Beidler, (2007). They mentioned that activities, meanings and physical attributes are components related to places that contribute to creating a sense of place. It is worth considering that each place was built for serving a specific action, meaning activity could refer to actions served by the place (Najafi and Shariff, 2011). As for physical elements, it indicates to the characteristics and attributes of a setting that define the kind of place it is. Additionally, it can also be said, as mentioned by Najafi and Shariff (2011) that sense of place is defined as an overall impression surrounding the general ways in which people feel towards places, sense them, and assign concepts and values to them.

In parallel, place relationships were related with sense of place, since place is fully made of concrete things that comprise of shape, texture, substance, materials, and colour, which together determine the essence of a place (Shinbira, 2012). It is the area where one is acquainted of the unique character of given localities and perception is enhanced. The faculty of recognising various places and distinguishing different identities of a place is attributed to the concept of sense of place. People are effected by places and reciprocally place is affected by people due to the attribution of meanings to physical forms. Subsequently an interaction occurs with a place rather than a response to a place, hence enriching the place with meanings. For this reason historical and heritage places carry more sense of place compared to contemporary modern places. Based on the aforementioned, this study looks into the role of characteristics of streets in terms of their physical and functional aspects, while excluding the meanings of street.

About place attachment, commencing by 1970th, phenomenological studies are the earliest sorts of literature introducing place attachment. Place attachment is associated with the development of affective connection between people or individuals and specific places which is expressed through "interplay of affects and emotions, knowledge and beliefs, and behaviours and actions" as Ujang and Shamssudin (2012) quoted from Altman and Low (1992). Attachments can be formed between people and buildings, environments, homes, objects, landscapes, neighborhoods, towns and cities. Alford (2011) mentioned that place attachment is as an affective bond that people establish with specific areas where they prefer to remain and where they feel comfortable and safe. Scannell and Gifford (2010) defined place attachment as an emotional bond. (Jorgensen and Stedman, 2005; Lewicka, 2008; Raymond, 2010) Place attachment refers to bonds that people develop with places.

This study will centre upon street as urban space. Hence, Lynch (1960) mentioned that street is very considerable elements in cities, which reflects the image and character of cities. Moughtin (2003) defined the street as one of the important elements that act as a public open space. According to Sulaiman et al. (2008) the street is one of the earliest components of the urban and plays the most important role as a channel for communication, also generates outdoor activities that are vital for the visual introduction of the urban dwellers.

Nowadays, the concept of sense of place and relationship between place and people are threatened by new developments, urban interventions, poor design and erosion in streets of towns and cities. These threatens lead to weakness the role of character and sense of place in streets (Sulaiman et al., 2008). Thus, streets in cities loss their historical and cultural values (Najafi and Shariff, 2011). Because of strong attendance of commercial activities, many people who live around streets move to another places. This led to imbalance state in cities and made them noisy and unsuitable for living (Ja'afar et al., 2012). Hence, changes of street activities reduce its importance as one of the main components which performs cities and urban fabric. All these reasons aid to loss sense, attachment and character of places (Ja'afar and Usman, 2009; Ujang, 2008).

According to the aforementioned introduction, the street is one important component of the city that can strongly reflect its character, sense of place and place attachment. This means that the street has attributors that give its sense of place and place attachment. Strength of sense of place and place attachment are evident of the multiplicity of street attributors. So, it is important to review these attributes.

\section{Attributes by which sense of place can be identified in streets:-}

Ja'afar et al. (2012), Lin (2011), Ja'afar (2006) and others who mentioned elements and features of streets to find the degree of sense of place. Physical and functional characteristics, and their division able to identify sense of place in open spaces or any place by brought about the relationship between it and its people (Lin, 2011). 


\subsection{Physical Characteristics:-}

Ja'afar et al. (2012) examines sense of place in traditional streets in Malaysia through three main qualities which are physical, activity, and meaning qualities to attract visitors. Physical quality encompasses physical elements (building and non-building). Activity quality encompasses activity element (formal and informal activity) and meaning quality encompasses meaning element (familiarity, historical and heritage).

Physical element is identified as the first important element contributing to sense of place in cities. It can be divided into two categories; buildings and non-buildings physical (Ja'afar and Usmar, 2009; Ja'afar et al., 2012 and 2008). The physical features plays an important role in influencing the sense of place (Ujang, 2008).

Buildings attract respondents to the street is associated with its use (activity inside the building). In the case, street character is reflected by the building use for business activities in all streets. For non-physical building, it is associated with presence of people. Meanwhile, non-physical building is associated with landscape element, soft and hard landscape. The mature trees are considered by respondents as a street symbol and contribute to the comfort environment which encourages a walkable atmosphere Ja'afar et al. (2012).

\section{(a) Accessibility:-}

Accessibility means the ability to easily get to and move through a place, thus provides ease of movement (Ujang, 2008). So, it is related to location of place. Location in context is one of the physical characteristics of the street (Shamsuddin, 1997). She finds that the location of the street becomes a recognisable feature, especially when its surrounding environment is easily identified. Streets and buildings are recognised by their location in relation to the buildings located adjacent to them or within their vicinity. Accessibility has two types: (a) Visual accessibility which allows people to see it and be informed about what is happening there, and (b) Physical accessibility which allows people to enter that space and use its functions. An urban public space should invite people to come inside and use its facilities (Jalaladdini and Oktay, 2012).

Each street forms both a destination and a connection to other places (South Gloucestershire Council, 2013). According to Ujang (2008), the location of the place play an important role in making the street accessible, particularly, when these streets are strategically located and are highly accessible from various locations, are well connected streets, are well connected pedestrian paths, and are accessible by various transport modes. These features of street location determine how the accessibility of a place is.

Ujang (2008) observed that street elements are vital in providing a foundation for an accessible built environment, while others (Ujang, 2008; Shamsuddin, 1997) noted they are important in recognising the street, especially buildings which act as landmarks. Places become more enjoyable to be in and more accessible to all when understanding and navigating through the built environment involves all of the senses through colour, light, shade, texture, sounds, and fragrances (Moreton Bay Regional Council, 2013). In this way, places can be designed to be easily comprehended and assist the individual to easily understand them, connect with them, use them and navigate through them (Moreton Bay Regional Council, 2013).

\section{(b) Recognition:-}

Recognition is another attribute of street that help to give a good sense to a place. People can recognize the street through its physical appearance. Physical form and appearance are the characteristics of the physical environment, especially buildings, which are distinctive and easily recalled (Shinbira and Sulaiman, 2010). Building and nonbuilding appearances are consist of style, form, facade, material, color, height, size, age, condition, roof form, and signage (Abbaszadeh, 2011; Grabler et al., 2008; Shamsuddin,1997). Also, people can realize the place by its building that can act as landmarks and nodes, and can be used in determining the path of place or street (BMS, 2011; Mohammed, 2010; Long et al., 2007; Lynch, 1981).

\section{(c) Sense of Safety and Comfort:-}

They are another street attributes related to landscape features. According to Ja'afar, et al. (2012), landscape features are one of the physical elements of the place. The landscape elements include trees (soft features) and street furniture (hard landscape elements) such as pavements, lighting, public art, and fences (London Borough of Croydon, 2009; Ja'afar and Usman, 2009). The success of any given place is highly influenced by the safety, comfort and convenience which people experience while pass through and/or go to places, spaces, and buildings (CABE, 2008). According to Ja'afar, et al. (2012), the presence of signs, lighting at night, sitting areas, trees, 
beautiful views, parking areas, facilities, and pavements with suitable width to walk on, contribute to making a comfortable environment. On the other hand, South Dublin County Council (2011) refers to six features that contribute in making the environment in street uncomfortable. These features are benches, dustbins, bicycle racks, bus stops, the quality of view, and pavements.

\subsection{Functional characteristics:-}

Historically, streets have played a very important role for a variety of reasons, such as providing an environment to meet friends and neighbours, being a platform for political protests, a location for markets and fairs, and even being a play area for children in the residential setting. The heart of economic and social activities in a city is traditionally situated in the city centre, as it is regarded the main source of commerce and labour (Rastegar, N. et al., 2014). Sammas (2008) quoted from Moughtin (2003) states that streets have functional elements in the city. They serve many functions; not only the movement of traffic, but also economic, political functions and social amenity. Thus, the street contributes in commerce and trading prosperity, and moving people from place to others, as well as reflects social and cultural values and importance. These attributes will be more discussed as the following.

\section{(a) Movement:-}

According to Al-Obeidy (2017) quoted from Telford (2007), movement is the most important feature in determining the character of a street, and it is the main functional role of the street (Leeuwen and Timmermans, 2006; Mahdzar, 2003). As a channel of movement, streets connect one place to another (Sholihah, 2005; Sammas, 2008). People use streets to move from one place to another by foot or by car. The street provides a link between buildings, both within the street and in the city at large. As a link, it facilitates the movement of people, as pedestrians or within vehicles, and the movement of goods.

\section{(b) Commerce and Trading:-}

They are second functional attributors of the street. Sholihah (2005) mentioned that people use streets as a place to offer goods and a place to display as much as they were "allowed". Pedestrians see, compare, discuss with their companions, bargain and decide whether to buy an item or not.

\section{(c) Social Values:-}

Streets can reflect the social values of communities because they present as arena for social expression (Moughtin, 2006). Street can provides eleven social uses of streets, including using the street for strolling and window-shopping, resting, people-watching, vendors, telephones, newspapers, art works and banners, schmoozing, eating, waiting, orientation or information seeking, street performers, drinking fountains, and finally fountains (Eichner and Tobey, 1987). Moreover, Ortiz (2012) points out to the successful public spaces where celebrations are held, where social interactions take place, where one finds and gathers with one's friends, where ideas are exchanged, where one expresses oneself, where one rests and observes, and where one finds the public institutions of cities.

The street is also an environment that offers multiple lessons for children just by watching people and their activities. Experiences in public spaces are not only a source for the education of children in learning how to cope with new situations in real life (Jacobs, 1961), but also for the education of adults in learning, by observing the way people do things differently (Lofland). Additionally, seeing other people engage in activities can be an inspiration to engage in new activities. Hence, even in contemporary times, the street, as a social space, can play multiple roles and offer social contact and interaction, social awareness and learning, and social cohesion. Therefore, Donnelley (2010, pp.38) emphasises that the design of all streets should recognise the importance of creating places for people to enjoy rather than simply providing corridors for the movement of traffic. Streets should generally be designed with a focus on social interaction.

\section{(d) Cultural Values:-}

According to Lai, et al. (2013), culture is one of the attributes to devote the significance of a place. Streets can provide cultural values which refer to refer to parades, street events, art performances, street musicians, traditional foods, culture-based goods such as crafts, and so forth, that form the life of a street (Sammas, 2008). According to McClinchey (2011), festivals, along with other leisure experiences, are perceived as important components of vibrant, diverse and creative urban spaces. Cultural festivals, in particular, are rapidly becoming an acceptable form of urban tourism in that they allow for the consumption of ethnic culture and are part of the overall experience economy. Cultural festivals have the potential to provide social benefits by contributing to a sense of shared identity, civic pride, cultural pride, community cohesiveness, place and belonging, and are also perceived as place image 
boosters. In his study, McClinchey (2011) concludes that festivals may contribute to a sense of place, but not substantially. The role of the festival was as a space for the showcasing and communication of culture, as a connection that ethno-cultural group leaders needed to maintain throughout the year in order to connect to broader meanings of place and identity. The festival allowed cultural entrepreneurs to value their own ethnic identity, maintain their cultural traditions and increase the awareness of their culture.

\section{Attributes by which place attachment can be identified in street:-}

Place attachment has empolyed by many researchers as (Ujang and Dola, 2007; Morgan, 2010; Ujang and Shamsuddin, 2008; Hidalgo and Hernandez (2001); Beidler, 2007). These authors and others divided place attachment to three categories namely, activity encompasses vitality, diversity and transaction, Physical elements encompass accessibility and legibility, and image encompasses distinctiveness, comfort, and safety and security.

\subsection{Activity:-}

Three of the key attributes of the activity contributing to place attachment are vitality, diversity and transaction. Available these activities able to make vibrant street.

\section{(a) Vitality:-}

Vitality means the capactity of the place to make multiple choices of activities used by users of street. A seccssful or responsive street able to fulfill human needs, and accomodate people activities (Jacobs, 1993). Firstly, continuous attributes of place have ability to create and enhance attachments between people and place. Secondly, pedestrian movement is an important factor to feed public space specially, streets. Thus, the number of people who visit street and presence of facilities un street have ability to make vibrant street (Montgomery, 1998).

\section{(b) Diversity:-}

Diversity is another atributes which has a poineer role in fostering place attachment in urban experience (Bentley et al., 1985). Many considerable researchers describe diversity as variety of building and facade forms, building types and activities. The best street has diversity in physical, social and economic aspects which make it more vital, active and safer (Jacobs, 1993).

\section{(c) Transaction:-}

It refers to good interaction between people and place. This positive interaction flows from positive surrounding atmosphere. Thus, the imoprtance of this aspect is evident in street life. Openning hour of shops able to develop economic activity in street (Montgomery, 1998). Moreover, presence of events, celebrations, occasions and meetings encourage on strengthen of place attachment and sense of welcoming in streets. Moreover, all these issues work together to create sense of place (Sulaiman et al., 2008) and contribute with the character of streets in towns and cities.

\subsection{Physical elements:-}

Two of the key attributes of the physical element contributing to place character are accessibility and legibility.

\section{(a) Accessibility:-}

Ujang (2008) mentioned that accessibiltiy determines uses and activities of places, these uses encompass location, visual cues, and legibility. It is means the ability to reach activities, services and people to place. Meantime, it means the ability to reach people from place to other places (Lynch, 1960). Here, should mention that connectivity plays important role in providing street's life. Connectivity is associated with the ability to easily get to and move through a place. Thus, it leads to safety and security concepts for users of these places (Commission of Architecture and the Built Environment, 2000).

\section{(b) Legibility:-}

Legibility is an attribute vital for good and successful places. A legible place is defined by vivid and integrated physical environment (Ujang and Shumsuddin, 2010). It eases the way of peoples' understanding, organizing and identifing their physical environment (Bentley et al., 1985). It explains how people can realize what apportunities a street can show. 


\subsection{Image:-}

Lynch (1960) explains the meaning of image and mentioned that streets are good places which reflect identity and image of place. Many scholars state how we can measure image of city and dertermine three aspects namely, distinctivenss, comfort, and safety and security.

\section{(a) Distinctiveness:-}

It related with character and identity of street because it means uniqueness that can distinguish one place from others (Relph, 1976). Distinctiveness determines the qualitiy of street and examine opinions of people in certain place. For example, ask people about do you have memories which relates you with this place? Why this place is important for you? This importance of imageability or legibility of place and its relation with sense of place that previously explained, Cadw's (2013, p.39) endeavours in making places legible is to make them easy to understand and navigate, so that people have a clear mental image of the place. He also emphasises that recognisable features or elements in a certain place contributes to give a sense of place. Since the place should be noticeable or recognisable through its physical characteristics, it is evident that the role of these characteristics is to make the street recognisable or noticeable or legible that make it distinctive.

\section{(b) Comfort:-}

Comfort is another attributes which give strong atachment between people and their place (Shamsuddin et al., 2008; Ujang, 2008). It performs successful streets in towns and cities. Comfort features generate sense of relaxing and sense of happiness by many elements such as landscape, water features and traffic free area. Thus, these issues will create beautiful and positive image for certain place or street, which received by its users or dwellers (Ujang and Shumsuddin, 2010; Lynch, 1960).

\section{(c) Safety and security:-}

Safety and security are the third contributes which have very important role to generate good image of city thus, strong attachments. Many aspects can encourage and strength safety such as presence of people, security officials and traffic free area in streets (PPS, 2013). Meanwhile, these aspects can reduce or deny the fear factor in peoples' feeling (Mehta 2007; Shamsulddin et al., 2008), crimes and bad events like, theft. Moreover, lighting of street is very important factor to available safety environment in streets.

\section{Measuring Street Attributes in terms of Sense of Place and Place Attachment:-}

Identifying street characteristics and attributes is related to perceptions and feelings of users. Sense of place is studied to understand or examine current people feelings and perceptions, while place attachment is related to the long term period and studied to examine the memory of people. On such basis, the streets attributes in terms of sense of place can be measured by asking people or users about their feelings, opinions, or perceptions like "how do you feel, understand, or use the street?", and "Why". For instance, "do you feel comfortable when you walk in the street?" and "why?" The answer of "Do" question will be yes or no. And the answer of "Why" question will determine the reason. On the other hand, place attachment means an effective or emotional bond that people establish with a specific place as mentioned in the introduction. This bond can be strengthened during the time. Thus, to know how to measure place attachment, the degree of relationship between people and place must be known. This can be obtained by asking people about the degree of their feelings and perceptions. This type of questions is called likert scale questions. For example, I feel comfortable when I walk in the street. The answer should be strongly disagree, disagree, agree or strongly disagree.

Previous research on perception, evaluation, imageability of place, sense of place, and place attachment are approached through the use of mixed methods, quantitative and qualitative techniques, which are employed by many considerable researchers as Shamsuddin (1997), Affendi (2004), Sulaiman and Shamsuddin (1998), Hilmilia (2005), Alford (2011), Fullerton (2011), Abbaszadeh (2011), Ujang (2008), Ja'afar (2006), Lin (2012), Shamsuddin and Ujang (2008), Ja'afar and Usman (2009), Ja'afar, et. al. (2012), Ujang and Dola (2007), Ja'afar, et al. (2008) Ujang and Shamsuddin (2008), Haji Bilyamin (2014), Lynch (1960), and Creswell (2003) (see Table 1.0). All of them find the combined methods as the most appropriate in their field of studies. 
Table 1.0:- Table of design methodology by researchers

\begin{tabular}{|c|c|c|c|c|}
\hline $\begin{array}{c}\text { The methodology used } \\
\end{array}$ & \multicolumn{2}{|c|}{ “Research Family" } & \multicolumn{2}{|c|}{ Relating Concept } \\
\hline $\begin{array}{c}\text { Types of Resources with their } \\
\text { Researcher (s) }\end{array}$ & Qualitative & Quantitative & Sense of Place & $\begin{array}{c}\text { Place } \\
\text { Attachment }\end{array}$ \\
\hline Haji Bilyamin, S. F. (2014) & $\mathbf{\square}$ & $\mathbf{\square}$ & $\mathbf{\square}$ & \\
\hline Alford S. R. (2011) & 口 & $\mathbf{\square}$ & $\mathbf{\square}$ & \\
\hline Fullerton K. R. (2011) & - & & $\mathbf{a}$ & \\
\hline Zadeh F. A. (2011) & $\mathbf{\square}$ & $\mathbf{\square}$ & $\mathbf{\square}$ & \\
\hline Ujang N. (2008) & $\mathbf{\square}$ & $\mathbf{\square}$ & & $\mathbf{\square}$ \\
\hline Baghi M. H. (2011) & $\mathbf{\square}$ & & $\mathbf{\square}$ & \\
\hline Ja'afar N. H. (2006) & $\mathbf{\square}$ & $\mathbf{\square}$ & $\mathbf{\square}$ & \\
\hline Sammas Y. A. A. (2008) & (a & & $\mathbf{\square}$ & \\
\hline Lin C. C. (2012) & - & $\mathbf{\square}$ & $\mathbf{\square}$ & \\
\hline Affendi Ahamad (2004) & 口 & $\mathbf{\square}$ & $\mathbf{\square}$ & \\
\hline Hilmilia Selamat (2005) & 口 & $\mathbf{\square}$ & $\mathbf{\square}$ & \\
\hline Shuhana Shamsuddin (1997) & $\mathbf{\square}$ & $\mathbf{\square}$ & & $\mathbf{\square}$ \\
\hline Ja'afar N. H. \& Usman I. M.S. (2009) & - & 口 & 口 & \\
\hline $\begin{array}{l}\text { Ja'afar N. H. \& Sulaiman A. B. and } \\
\text { Shamsuddin S. (2012) }\end{array}$ & $\mathbf{\square}$ & $\mathbf{\square}$ & $\mathbf{\square}$ & \\
\hline Ujang N. and Dola K. (2007) & $\mathbf{\square}$ & $\mathbf{\square}$ & $\mathbf{\square}$ & $\mathbf{\square}$ \\
\hline $\begin{array}{l}\text { Ja'afar N. H., Usman I.M.S., Tahir } \\
\text { M.M., Mohd Nor M.F. I. (2008) }\end{array}$ & $\mathbf{\square}$ & $\mathbf{\square}$ & $\mathbf{\square}$ & \\
\hline Ujang, N. and Shamsuddin, S. (2012) & - & 口 & & $\mathbf{\square}$ \\
\hline Ujang N. \& Shamsuddin S. (2008) & $\mathbf{\square}$ & $\mathbf{\square}$ & $\mathbf{\square}$ & \\
\hline $\begin{array}{l}\text { Ja'afar N. H., Sulaiman A. B. \& } \\
\text { Shamsuddin S. (2012) }\end{array}$ & $\mathbf{\square}$ & $\mathbf{\square}$ & $\mathbf{\square}$ & \\
\hline Shinbira and Sulaiman (2010) & $\mathbf{\square}$ & $\mathbf{\square}$ & $\mathbf{\square}$ & \\
\hline
\end{tabular}

For example, the study of Shinbira and Sulaiman (2010), also adopted the mixed method to support evidence and examine the physical and functional characteristics associated with street identity. Moreover, Abbaszadeh (2011) studied the characterisation of the physical elements of street design by using the mixed method to collect data.

Hence, the research suggests that the use of the mixed method can provide the study with a more complete understanding of the phenomena and support the findings. This study tries to explain how to achieve integrated methods of studying influential attributes of street in terms of sense of place and place attachment.

\section{Conclusion:-}

Streets are an important icon of city. They have had pioneer role in strengthening of relationships among people, producing of services like shopping, by brought about vitality, diversity and transaction which reflect good place attachment, and functional and physical characteristics which reflect charm sense of place of streets in towns and cities. Figure 1.0 shows the theoretical framework of the study. It explains street characteristics and their attributes in relating firstly to sense of place and secondly place attachment. Commerce, cultural value, social value, and movement are functional contributors of street in terms of sense of place, while accessibility, legibility, recognition, sense of comfort, and sense of safety are its physical contributors. In terms of place attachment, the attributors of activity in the street are vitality, diversity, and transaction, the attributes of physical elements are accessibility, and legibility, the attributors of image are distinctiveness, comfort, and safety and security. 


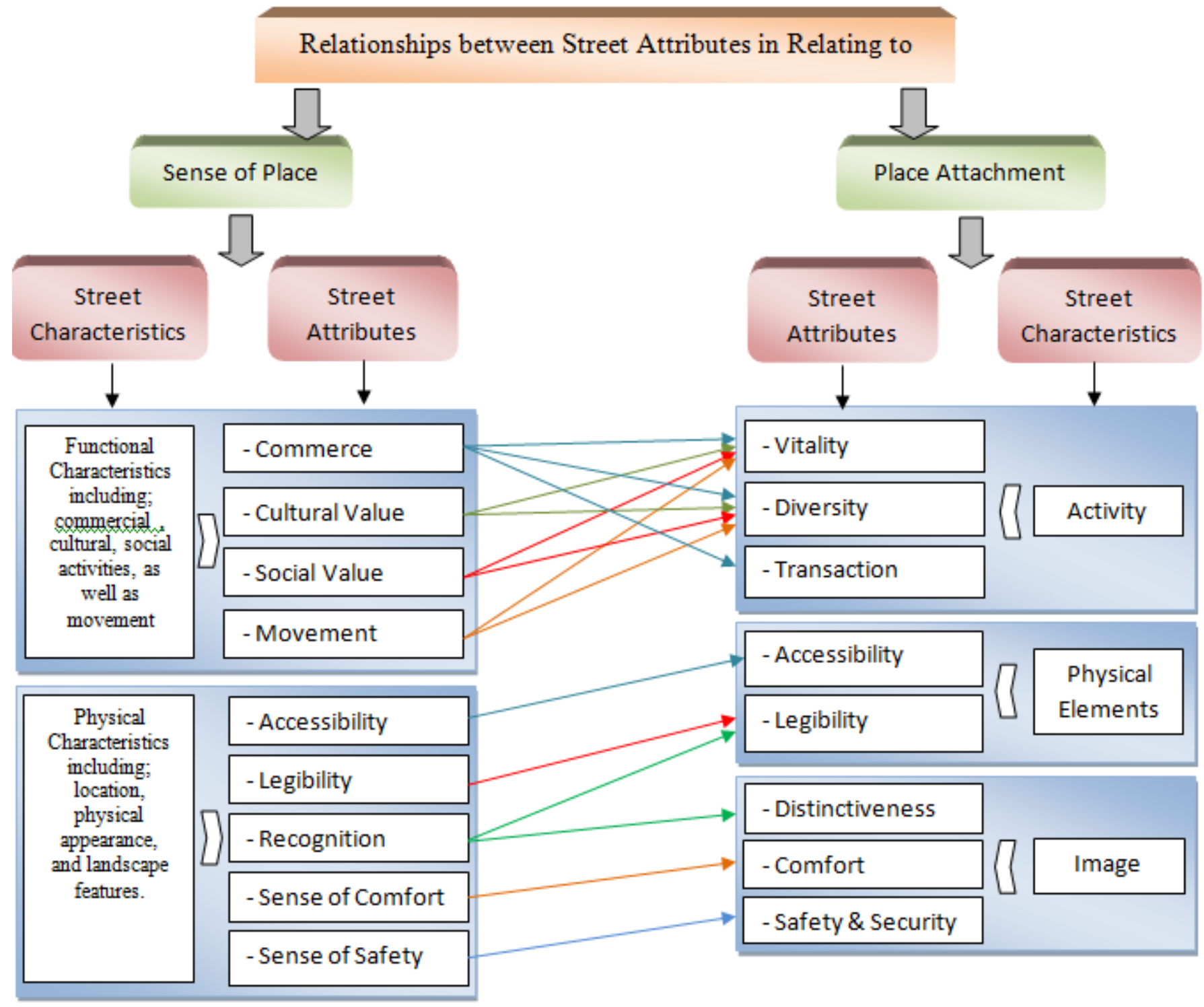

Figure 1.0:- Theoretical Framework that Explains the street Characteristics and Attributes, and their Relationships for Two Concepts, Sense of Place and Place Attachment.

To secure streets characteistics and keep unique character of city centers, the achieving sense of place should be seeked firstly then place attachment. It means that the feelings or senses that affect people positively should be created first to make strong place attachment. No attachement (relationships between person and place) without sense of place (good feelings and emotions) first. Thus, both of sense of place and place attachement are important and conrtibute to secure the character of streets' city centers. Place makers, developers, and designers should take into consideration enhancing sense of any place through design and improve its functional and physical characteritics that contribute in making good senses or feelings to its users. Besides, activity, physical elements, and image are key attributes of streets to setrengthen sense of attachement or belonging. 


\section{References:-}

1. Alford, S. R. (2011). An Exploration of the Attributes of Sense of Place in A Culturally-Diverse Dallas District: Learning From Cedar Springs. Unpublished Master's Thesis. The University of Texas at Arlington.

2. Al-Obeidy, M. S. and Shamsuddin, S. (2017). The Role of Commercial Streets as a Channel of Movement in Relating to the Sense of Place. International Journal of Advanced Research (IJAR). 5(1), 1598-1607

3. Bassett, M. A. (2011). The Role Of Historic Resources in Fostering Sense of Place: A Study of Sense of Place in Uptown and Tierrasanta, San Diego. Thesis .

4. Beidler K. J. (2007). Sense of Place and New Urbanism: Towards a Holistic Understanding of Place and Form. Unpublished PhD Thesis. the Virginia Polytechnic Institute and State University.

5. Bentley, I., Alcock, A., Murrain, P., McGlynn, S., and Smith, G. (1985). Responsive Environments: A Manual for Designers. Architectural Press: London, p. 363- 365

6. Commission of Architecture and the Built Environment (2000). By Design: Urban Design in the Planning System: Towards Better Practice. London: Thomas Telford Publishing.

7. Hidalgo, M. C. and Hernandez, B. (2001). Place Attachment: Conceptual and Empirical Questions. Journal of Environmental Psychology. (2001) 21, 273-281.

8. Ja'afar, N. H., and Sulaiman, A. B. and Shamsuddin, S. (2012). Traditional Street Activities in Kuala Lumpur City centre. International Journal of Multidisciplinary Thoughts. Volume 2 (1) , P. 93-105.

9. Ja'afar, N.H., Usman, I. M.S., Tahir, M.M., and Nor, M.F. I. M. (2008). Activity Element Of Traditional Street In Attracting Visitor. Journal of Design+ Built. volume(1), p. 15-20.

10. Ja'afar, N. H. and Usman, I. M. S. (2009). Physical and Transportation Elements of Traditional Street in Malaysia. Volume 9, Number 4, p.669- 676.

11. Ja'afar, N. H. (2006). Criteria "Success" in the Traditional Way to Attract Visitors: Kuala Lumpur: A Case Study. Unpublished Master's Thesis. Universiti Teknologi Malaysia, Skudi.

12. Jacobs A.B. (1993). "The Great Streets". United States of America: The MIT Press.

13. Jorgenson, B.R. and Steadman, R.C. (2005). A Comparative Analysis of Predictors of Sense of Place Dimensions: Attachment to, Dependence on, and Identification with lakestore Properties. Journal of Environmental Management, 1-12.

14. Lewicka, M. (2008). Place attachment, Place Identity, and Place Memory: Restoring the Forgotten City Past. Journal of Environmental Psychology. 28 (2008), 209-231.

15. Lin, C. C. (2011). Sense of Place, Protected Areas and Tourism: Two Tasmanian Case Studies. Unpublished $\mathrm{PhD}$ thesis. University of Tasmanian.

16. Lynch, K. (1960). The Image of a City. Cambridge Massachusetts.

17. Morgan, P. (2010). Towards a Developmental Theory of Place Attachment. Journal of Environmental Psychology. 30 (2010) 11-22.

18. Mehta, V. (2007). Lively Streets: Determining Environment Characteristics to Support Social Behaviour. Journal of Planning Education and Research. 27, 165-187.

19. Montgomery, J. (1998). Making a City: Urbanity, Vitality and Urban Design. Journal of Urban Design, 3(1), 93-116.

20. Moughtin, C. (2003). Urban Design: Streets and Square. (3th ed.) London: Elsevier's Science and Technology Rights Department in Oxford.

21. Najafi, M. and Shariff, M. K. M. (2011). The Concept of Place and Sense of Place in Architectural Studies. International Journal of Human and Social Sciences. 6:3. p. 187- 193

22. PPS (2013, July 13 and 14). Streets as Places. Retrieved on May 1, 2013, from http://www.pps.org

23. Raymond, C. M., Brown, G., and Weber, D. (2010). The Measurement of Place Attachment: Personal, Community, and Environmental Connections. Journal of Environmental Psychology. 30 (2010), 422-434.

24. Relph, E. (1976). Place and Placelessness. London: Pion. Volume (1), number (1), p. 54- 57

25. Scannell, L. and Gifford, R. (2010). Defining Place Attachment: A Tripartite Organizing Framework. Journal of Environmental Psychology. 30 (2010), 1-10.

26. Shamai, S. (1991). Sense of Place: an Empirical Measurement. Geoforum, 22(3): 347-358

27. Smaldone, D. (2006). The Role of Time in Place Attachment. Proceedings of the 2006 Northeastern Recreation Research Symposium: GTR-NRS-P-14, 47-56

28. Shinbira, I. A. (2012). Conservation of the Urban Heritage to Conserve the Sense of Place, a Case Study Misurata City, Libya. 2nd International Conference-Workshop on Sustainable Architecture and Urban Design 2012. 3-5 March, 2012, School of Housing, Building and Planning, Universiti Sains Malaysia, Penang, Malaysia. 
29. Shinbira, I. A., and Sulaiman, A. B. (2010). Physical Qualities and Activities Patterns Associated with Street's Identity, A Case Study Jalan Tuanku Abdul Rahman- Kuala Lumpur, Malaysia. pp.390-399.

30. Sulaiman, A. B., Shamsuddin, S., and Ja'afar, N. H. (2008). The Traditional Shopping Streets and its Attractions to the Users. Sulaiman, A. B. and Mai, M. M. (Eds.). Urban Design Issues in the Developing World, The Case Study in Malaysia and Nigeria. Malaysia: Universiti Teknologi Malaysia. p.42-64.

31. Ujang, N. (2008). Place Attachment Towards Shopping District in Kuala Lumpur City Centre. Unpublished $\mathrm{PhD}$ Thesis. Universiti Putra Malaysia.

32. Ujang, N. and Dola, K. (2007). Linking Activity and Place Attachment Dimensions in Enhancing the Sense of Place. Alam Cipta, International Journal on Sustainable Tropical Design Research and Practice. 2 (1). pp. 5967. ISSN 1823-7231.

33. Ujang, N. and Shamsuddin, S. (2008). Place Attachment in Relation To Users' Roles in The Main Shopping Streets of Kuala Lumpur. Sulaiman, A. B. and Mai, M. M. (Eds.). Urban Design Issues in the Developing World, The Case Study in Malaysia and Nigeria. Malaysia: Universiti Teknologi Malaysia, p. 22-42.

34. Ujang, N. and Shamsuddin, S. (2010). The Influence of Legibility on Attachment towards the Shopping Streets of Kuala Lumpur. Pertanika J. Soc. Sci. \& Hum. 20 (1): 81 - 92. 